\title{
TIM Lecture Series: The Importance of Dealing with Risk for New Businesses
}

\author{
Tony Lackey
}

\author{
(6 So many people think, 'It will never happen here.')" \\ The truth is that it can happen. And if it does, it will \\ happen at the worst possible time. \\ Tony Lackey \\ Risk and Insurance Manager \\ Carleton University
}

\begin{abstract}
The second TIM Lecture Series of 2012 was presented by Tony Lackey, Risk and Insurance Manager at Carleton University. Tony drew upon his extensive experience in insurance claims and risk management to demonstrate the key aspects of these topics for new businesses owners. The presentation was targeted at early-stage technology companies, but the key concepts can be applied more broadly. The event was held at Carleton University in Ottawa, Canada, on March 21, 2012. This report summarizes the presentation and its key messages, including important takeaways identified by audience members.

The TIM Lecture Series is hosted by the Technology Innovation Management program (TIM; carleton.ca/tim) at Carleton University. The lectures provide a forum to promote the transfer of knowledge from university research to technology company executives and entrepreneurs as well as research and development personnel. Readers are encouraged to share related insights or provide feedback on the presentation or the TIM Lecture Series, including recommendations of future speakers.
\end{abstract}

\section{Summary}

Tony Lackey began the presentation by defining risk and explaining the importance of risk management. Risk relates to uncertain events and outcomes; while there are many types of risk that will be encountered in a business, some have minimal impact and can be managed easily, while others may threaten the longevity of a business. Business owners should weigh the importance of potential risks by assessing the frequency and severity of events and then take action to mitigate the most important threats to the business.
Next, Tony discussed the top-10 risks that a new business will face:

\section{Property losses}

2. Liability losses

3. Business interruption

4. Key person losses

5. Injuries to employees 


\section{TIM Lecture Series: The Importance of Dealing with Risk for New Businesses}

\section{Tony Lackey}

\section{Losses of electronic data and computer resources}

7. Credit risk (e.g., customers that do not pay)

8. Employment practice risks

\section{Contract risks}

\section{Supply chain risks}

The presentation highlighted that risk-management principles and techniques can be applied broadly; they are worth knowing about and applying to both business and everyday life. In building the case for integrating a risk-management framework into a new business, Tony emphasized that: "Understanding the principles and processes for effective risk management will help a business owner make the decisions necessary to ensure the best possible outcome for the business." He suggests the following steps in developing a risk-management framework:

\section{Identify risks}

A number of techniques can be used to identify risk, including brainstorming, surveys, examining reports and financial statements, envisioning worst-case scenarios, and benchmarking. Ideally, every business should make these activities part of an annual risk assessment.

\section{Evaluate risks}

Once the various risks have been identified, their importance can be evaluated and ranked based on the likelihood that each even will happen and the severity of the outcomes should it occur. The highest-ranked risks should attract the greatest amount of resources and planning effort. As part of this step, not only are the risks evaluated, but the company's tolerance (or appetite) for risk can be established.

\section{Identify and implement risk-management techniques}

There are four basic categories of risk-management techniques, the details of which were discussed in the second half of the presentation:

1. Reduce the risk through preventative effort (e.g., smoke detectors, safety procedures).

2. Assume or retain the risk (e.g., opting for a high deductible on an insurance policy).

3. Combine the risk (e.g., insurance policies combine the risks - and premiums - of many organizations, of which only a small number make claims).
4. Transfer the risk (e.g., terms in a contract that specifies that the other party owns particular risks).

Monitor and improve the risk-management program A risk-management program should be evaluated on an ongoing basis based on the results the program achieves. If the desired results are not being met, the program should be re-evaluated and the mitigation strategies should change.

In the final portion of the presentation, Tony revisited the top-10 risks that a new business will face and provided more detail about the specific risk management techniques that are relevant to each type. The discussion emphasized the following:

1. Mitigating against losses to company property through insurance and common sense

2. Selecting appropriate types of insurance and levels of coverage with the advice of insurance professionals

3. Understanding common insurance exclusions

4. Protecting intellectual property through copyright, patents, and trademarks

5. Protecting a new business from different types of liability

6. Interpreting common contract terms that relate to liability

\section{Lessons Learned}

1. A company's risk exposure changes as it grows. The greatest amount of risk must be assumed in the company's early-stages.

2. Risks are always present, but mitigation can lower either the severity of frequency of risks, thereby lowering the potential impacts to your company.

3. A fundamental way of evaluating risks is to multiply the likelihood that each event will occur by its severity. Mitigate risks that come up as most important.

4. Risks to a company's reputation are paramount. Many other risks follow on from this one.

5. The moment of loss is not the time to start thinking about risk. Have a plan in place before something happens. 


\section{TIM Lecture Series: The Importance of Dealing with Risk for New Businesses}

\section{Tony Lackey}

6. A backup plan can provide peace of mind, the value of which should not be underestimated. Knowing you have a plan in place leads to increased confidence, which frees you up to pursue opportunities rather than stress about what might happen. With confidence you can focus on growing your business and making decisions.

7. An added benefit of putting together a solid risk-management plan is the capacity of the company to then take on further risk, which can help grow the business.

8. As a startup, you may encounter potential customers that are reluctant to enter into a contract with you because they fear you will go out of business. If they know you have a solid risk management plan in place, it can increase their confidence in you and therefore increase their willingness to do business with you.

9. Risk management is important and complex, but sources of advice are available. The decision of whether or not to pay for some of this advice (e.g., from lawyers) is a risk-management exercise in and of itself.

10. Risk management is an ongoing process. As the environment changes, the likelihood or severity of existing risks may increase or decrease, and new risks may appear.

\section{About the Author}

Tony Lackey is Manager of Risk and Insurance at Carleton University in Ottawa, Canada, where he also lectures in the Sprott School of Business. Prior to coming to Carleton, he spent over 18 years in the general insurance industry, the last four of which in the role of Regional Claims Manager at a large Canadian mutual insurance company. Tony also operating an independent consulting business where he offered technical audit services and developed claims systems. He has also held executive positions with several insurance and non-profit organisations. Tony holds a BA from Carleton University and the Certified Risk Manager (CRM) designation. He is also a Fellow of the Global Risk Management Institute and a Fellow Certified Insurance Professional. He is an active member of the Risk and Insurance Managers Society and is Past-President of the Ottawa chapter.

Citation: Lackey, T. 2012. TIM Lecture Series: The Importance of Dealing with Risk for New Businesses. Technology Innovation Management Review. April 2012: 41-43. 